\title{
Anabolic steroid use among students at a British college of technology
}

\author{
D. J. Williamson MRCPsych \\ Oxford University Department of Psychiatry, Psychopharmacology Research Unit, Littlemore Hospital, Oxford, \\ UK
}

\begin{abstract}
To determine the rate of current or previous use of anabolic steroids by students at a UK college of technology, a questionnaire survey of 687 day students was conducted. The questionnaire began with a general section for all of the students, which ended with the question 'Have you ever used anabolic steroids?'. A further section specifically for anabolic steroid users examined patterns of use, and how certain circumstances might affect the individual's decision to use anabolic steroids. The response rate to the questionnaire was $92 \%$. The overall rate of current or previous use of anabolic steroids was $2.8 \%(4.4 \%$ in males, $1.0 \%$ in females). Of these, $56 \%$ had first used anabolic steroids at age 15 or less. Anabolic steroid users were more likely to be male, under 17 years of age, and participating in bodybuilding, weight-lifting or rugby. The results of this survey, if confirmed in other groups of young people, would suggest that use of anabolic steroids may be widespread in the UK.
\end{abstract}

Keywords: Anabolic steroids, drug use, students

The use of anabolic steroids carries the risk of serious physical and psychological consequences ${ }^{1,2}$. Despite this, they are commonly used by top class amateur athletes and professional sportsmen and sportswomen $^{3}$. Is anabolic steroid use confined to this relatively small number of individuals or does it also occur outside the competitive arena? Over the last 12 years an on-line computerized literature search (Medline) has revealed only American attempts to establish the prevalence of anabolic steroid use outside competition. Buckley et al. ${ }^{4}$ conducted a survey of 3403 male 12th grade high school students from across the USA. Response rate to a questionnaire was $50.3 \%$. The rate of current or previous anabolic steroid use was $6.64 \%$. One third of anabolic steroid users first used the drugs at age 15 or less. Windsor and Dumitru ${ }^{5}$ surveyed 1010 high school students, with a questionnaire response rate of $89 \%$. Of these students $3 \% \quad(5.0 \%$ of males, $1.4 \%$ of females) reported anabolic steroid use. Pope et al. ${ }^{6}$

Address for correspondence: Dr D. J. Williamson, Research Psychiatrist and Honorary Senior Registrar, Oxford University Department of Psychiatry, Psychopharmacology Research Unit, Littlemore Hospital, Oxford, OX4 4XN, UK

(C) 1993 Butterworth-Heinemann Ltd 0306-3674/93/030200-02 surveyed 1010 male students in three American colleges and $2 \%$ of respondents reported anabolic steroid use. The questionnaire response rate was $30 \%$. Although it is suspected that a similar situation may exist in this country ${ }^{7}$, this is the first formal survey of the prevalence of anabolic steroid use among British college students.

\section{Method}

Dumfries and Galloway Health Board Ethics (Research) Committee approved the study. The questionnaire designed by Buckley et al. ${ }^{4}$ was used, modified slightly for a British population. Questionnaires were handed out by class lecturers to all students (except those at evening classes) attending a college of technology during the week 23-27 March 1992. The questionnaire was completed anonymously. All respondents completed an initial section which comprised 11 questions, the last of which was 'Have you ever used anabolic steroids?'. (Anabolic steroids were defined in the questionnaire as 'drugs used by some people to increase their strength or size, or to improve athletic performance'.) Those who answered 'yes' to this were directed to a further section examining patterns of use and how certain circumstances might influence the individual's decision to use anabolic steroids. Those who answered 'no' were directed to a different section examining health behaviour. This design was intended to result in similar completion times for both groups and thus preserve anonymity. To measure the significance of differences between groups $\chi^{2}$ (Yates Correction) tests were used.

\section{Results}

In all, 687 students were given questionnaires; 633 replied (a $92 \%$ response rate). A wide range of students participated in the survey, from those in academic courses leading to a Higher National Certificate, to those attending practical courses such as nursery nursing, mechanics and hairdressing. Of the students participating, $14 \%$ were under 17 years of age, $47 \%$ were $17-19$, and $39 \%$ were 20 or older.

Current or previous anabolic steroid use was reported by 18 students, a rate of $2.8 \% \quad(4.4 \%$ of males, $1.0 \%$ of females). Of these, $10(56 \%)$ had first 
used anabolic steroids at age 15 or less, and $14(78 \%)$ at age 17 or less. Current use was reported by $9(50 \%)$ students; $16(88 \%)$ had used the drugs for three or more 'cycles' of less than 9 weeks duration; $6(33 \%)$ had used oral and injectable steroids concurrently (a practice known as 'stacking'). The most common reasons given for anabolic steroid use were 'to improve appearance/physique' (39\%) and 'to improve sporting performance' $(22 \%)$. Anabolic steroids were obtained via 'the black market' $(28 \%)$, mail order $(22 \%)$, a health professional $(17 \%)$ or an unspecified source (33\%).

Most users said they would stop taking anabolic steroids if it was proved that they led to permanent sterility $(55 \%)$, an increased risk of liver cancer $(56 \%)$ or an increased risk of a heart attack before the age of $40(62 \%)$. However, only $34 \%$ said that they would stop if their competitors were not using them.

When compared with non-users, those reporting anabolic steroid use were more likely to be male $(83 \%$ versus $53 \%, P=0.02)$, under 17 years of age $(33 \%$ versus $13 \%, P=0.03)$, and participating regularly in sport $(94 \%$ versus $70 \%, P<0.05)$. They were more likely to report their strength as 'better than average' (50\% versus $14 \%, P=0.0001$ ). Compared with non-users who participated regularly in sport, anabolic steroid users were more likely to participate in bodybuilding (50\% versus $4 \%, P<0.0001$ ), weightlifting (44\% versus $16 \%, P<0.01)$ and rugby $(50 \%$ versus $5 \%, P<0.0001$ ). Of the users $39 \%$ estimated the number of male students at the college who had taken anabolic steroids as 'more than 40 ' compared with only $8 \%$ of non-users $(P<0.0001)$.

\section{Discussion}

This survey suggests that approximately $4.4 \%$ of males and $1 \%$ of females at the college use or have used anabolic steroids. In a survey of this nature under-reporting is a possibility, and it is worth noting that nearly two-thirds of the anabolic steroid users estimated the number of male users at the college as considerably higher than the figure obtained in the survey. A significantly greater proportion of users at the college was under 17 years of age. There could be at least two possible reasons for this. First, the drugs may have only recently been introduced to young people at the college. Second, the drugs may be taken mainly by adolescents who 'grow out' of taking them by their twenties. Anabolic steroids were most commonly taken simply with the aim of enhancing physical appearance. Half of the users participated in rugby, a sport not traditionally associated with anabolic steroid use.

The survey involved only one college, and the results may not generalize to other colleges. One distributor of anabolic steroids might be sufficient to account for all the users in this survey, although the range of sports in which participation was reported does not suggest that they were all part of the same group.

The numbers in this survey are relatively small but the results, if confirmed in other groups of young people, would suggest that use of anabolic steroids may be widespread in the UK. Anabolic steroid use may start at school, and the reported attitudes of users suggest that education at school age with respect to potential deleterious effects of anabolic steroid use on health may be an effective adjunct to legislation.

This study warrants replication, and should be repeated in other colleges and in schools.

\section{Acknowledgements}

I would like to thank the staff and students of the college for their cooperation. I am also grateful to Dr R. G. McCreadie for advice, and Mrs M. McCormick for clerical assistance.

\section{References}

1 Wilson J. Androgen abuse by athletes. Endocr Rev 1988; 9: 181-99.

2 Williamson DJ, Young AH. Psychiatric effects of androgenic and anabolic-androgenic steroid abuse in men: a brief review of the literature. Journal of Psychopharmacology 1992; 6: 20-6.

3 Haupt HA, Rovere GD. Anabolic steroids: a review of the literature. Am J Sports Med 1984; 12: 469-84.

4 Buckley WE, Yesalis CE, Friedl KE, Anderson WA, Streit AL, Wright JE. Estimated prevalence of anabolic steroid use among male high school seniors. JAMA 1988; 260: 3441-5.

5 Windsor R, Dumitru D. Prevalence of anabolic steroid use by male and female adolescents. Med Sci Sports Exerc 1989; 21: 494-7.

6 Pope HG, Katz DL, Champoux R. Anabolic-androgenic steroid use among 1010 college men. Phys Sportsmed 1988; 16: 75-81.

7 Pate R, Temple DJ. The use of anabolic steroids in Wales. Crown Offices, Cardiff, UK: Welsh Committee on Drug Misuse (Report), 1992. 